\title{
Meeting a person with pedophilia: Attitudes towards pedophilia among psychology students: A pilot study
}

\author{
Rebecca L. Heron ${ }^{1,2}$ (1) $\cdot$ Lena Schwiekert ${ }^{2} \cdot$ Julie Karsten $^{2}$ \\ Accepted: 14 January 2021 / Published online: 23 February 2021 \\ (C) This is a U.S. government work and not under copyright protection in the U.S.; foreign copyright protection may apply 2021
}

\begin{abstract}
People with pedophilia (PWP) are highly stigmatized. Public opinion is strongly pre-consolidated - it is often assumed that every PWP commits child sex offenses. This presumption not only affects PWP negatively. Research suggests that this stigmatization may cohere with PWP actually committing child sex offenses. Various recent studies have investigated different kinds of antistigma interventions and their effectiveness. Direct contact to a PWP has not yet been investigated. The present pilot study aimed at finding out whether a dichotomous anti-stigma intervention can change psychology students' attitudes towards PWP regarding perceived dangerousness, intentionality, deviance, and punitive attitudes. In a one sample pre-post design, we presented 162 students of the University of Groningen with both an educational lecture and direct contact to a PWP. Participants learned about child sex offending and pedophilia. Then, Gabriel, a PWP shared his experiences about growing up, coping, and living with pedophilia. Results of the one-sample Wilcoxon signed-rank test revealed significantly diminished negative attitudes towards PWP after the intervention. Students perceived PWP as less dangerous, having less intent, and being less psychologically deviant. Additionally, students' punitive attitudes towards PWP diminished significantly. Also, a thematic analysis revealed that students were highly interested in the topic of pedophilia and greatly appreciative of Gabriel sharing his story. This pilot study was the first to provide evidence for the effectiveness of a combination of an educational lecture and direct contact to a PWP as an anti-stigma intervention.
\end{abstract}

Keywords Pedophilia $\cdot$ Anti-stigma intervention $\cdot$ Punitive attitudes $\cdot$ Direct contact

The Diagnostic and Statistical Manual of Mental disorders (now in its 5th edition, DSM-5, American Psychiatric Association, 2013) defines pedophilia as the sexual attraction to prepubescent children. The pedophilic disorder is defined as the repetitive and intensive sexual attraction to prepubescent children for at least six months. Additionally, sexual urges have been acted upon or caused severe distress or interpersonal difficulty. Thus, it is essential to note that the term pedophilia does not necessarily imply sexual misconduct or clinical diagnosis. To be diagnosed with pedophilic disorder, an individual needs to have acted on these sexual urges or be severely impaired by them. When referring to an individual as

Rebecca L. Heron

HeronR@uhv.edu

1 Department of Arts and Sciences, University of Houston-Victoria, 3007 N. Ben Wilson, Victoria, TX 77901, USA

2 Department of Clinical Psychology and Experimental Psychopathology, University of Groningen, Groningen, the Netherlands a PWP, it is unclear whether the individual solely has a pedophilic interest or suffers from pedophilic disorder. In this paper, the term PWP will be referring to someone experiencing sexual attraction to prepubescent children, regardless of whether he/she suffers from the attraction (pedophilic disorder) or not (sexual preference).

A person committing a child sex offense is a person who sexually offended against a child - but not necessarily a PWP. For instance, the first case involves a behavioral action of what one decides to do; whereas the second case a PWP, is referring to having an attraction to minors, but this is not voluntarily chosen or necessarily acted upon. Accurately differentiating between the classifications of persons who sexually offended against children and PWP is essential for societal, clinical, judicial, and research purposes (Feelgood \& Hoyer, 2008).

The public commonly uses both terms interchangeably (Harper, Bartels, \& Hogue, 2018). Harper et al. (2018) assumed that people are unaware of the differences between the two constructs. This has severe implications. For example, people often perceiving PWP to be dangerous (Imhoff, 2015). If people equate persons who have sexually offended against a 
child with PWP, it follows that every PWP has sexually offended against a child (Feelgood \& Hoyer, 2008) and vice versa. This line of thinking might partly explain why in contemporary society, it is socially desirable to hold punitive attitudes towards PWP (Imhoff, 2015). However, previous research indicates that not every person who has sexually offended against a child is a PWP (Schmidt, Mokros, \& Banse, 2013). Up to $80 \%$ of persons incarcerated for sexually abusing a child are not PWP, nor do they suffer from pedophilic disorder and, therefore, do not have any sexual preference for children at all (Seto, 2018; Walker \& Panfil, 2016).

Despite this distinction between PWP and persons who sexually offended against children, the mainstream media commonly labels perpetrators of child sex offenses as "violent criminal pedophiles" (Quinn, Forsyth, \& Mullen-Quinn, 2004). Most people do not inform themselves explicitly about the differences between PWP and persons who have sexually offended against children, but rather tend to rely on the media for information (Wurtele, 2018). Another common misunderstanding is shown by King and Roberts (2017) who showed that people often believe that a person who has sexually offended against a child must be a predatory pedophile. This is also strengthened by the media (Harper \& Hogue, 2017), which could partly explain people's tendency to discriminate against PWP regardless of their actual behavior (Jahnke \& Hoyer, 2013). In 2018, Jahnke tried explicitly informing participants that a PWP has never and will never commit a sexual offense. Nevertheless, the participants considered the PWP to be dangerous.

This stereotypic idea of a PWP has negative consequences for PWP and hinders effective preventive treatment programs and, therefore, presumably puts more children at risk. Therefore, the importance of anti-stigma interventions must be realized and acted upon (Jahnke, Imhoff, \& Hoyer, 2015a). PWP experience negative mood, reduced self-esteem, high social isolation, distress, and loneliness (B4U-ACT, 2011; Cash, 2016). Unfortunately, instead of seeking professional help, many PWP believe that health care professionals will treat them in a stigmatized way (Kramer, 2011), and, therefore, refrain from seeking help. When looking at previous studies, this belief is not that far-fetched: Stiels-Glenn (2010) found that $95.5 \%$ of German psychotherapists were unwilling to treat PWP. Reasons were provided, lack of sufficient training being one of them. Although not explicitly stating negative attitudes as a reason, one could assume that they have played a role to some extent.

Further, and probably as a result of negative attitudes towards PWP, people hold beliefs about PWP, such as they should be "incarcerated" or even "better dead" (Jahnke, Imhoff, \& Hoyer, 2015a). These negative attitudes towards PWP have been shown to exist worldwide, such as in Germany (Imhoff, 2015; Jahnke, Imhoff, \& Hoyer, 2015a; Jahnke, Philipp, \& Hoyer, 2015b; Stiels-Glenn, 2010), the
United States (Imhoff, 2015; Imhoff \& Jahnke, 2018; Jahnke, 2018a; Jahnke, Imhoff, \& Hoyer, 2015a), the United Kingdom (Feldman \& Crandall, 2007; Harper \& Hogue, 2015), and Russia (Koops, Turner, Jahnke, Märker, \& Briken, 2016). In light of those negative attitudes, it is not surprising that PWP have a hard time disclosing their attraction and feel discouraged from requesting help from professionals or family and friends (Kramer, 2011; Seto, 2012). Moreover, even if they are trying to, treatment opportunities for PWP are hard to find (Lasher \& Stinson, 2017).

According to the World Health Organization (WHO Regional Office for Europe, 2013), approximately 150 million girls and 73 million boys worldwide experience sexual abuse before turning 15 years of age (WHO Regional Office for Europe, 2013). Treatment must be made available to PWP, as this is likely to be more effective in reducing child sexual abuse than simply ostracizing PWP until they become offenders (Jahnke \& Hoyer, 2013; Lasher \& Stinson, 2017).

\section{The Present Pilot Study}

This pilot study was conducted with psychology students of the University of Groningen to shed light on whether psychology students in the Netherlands hold punitive attitudes towards PWP. The only other study of this kind was conducted in the United States and highlighted that psychology students had negative perceptions toward PWP (Wurtele, 2018). It is crucial to understand stigma among psychology students since they have a higher chance of working with PWPs than other students. Previous research also suggests that negative attitudes toward PWP are not reserved for older and uneducated people, but young and educated people share them too (Imhoff \& Jahnke, 2018; Jahnke, 2018a, b; Jahnke, Imhoff, \& Hoyer, 2015a).

The theoretical underpinning of the present pilot study is based on the concept of attitudes and the contact hypothesis by Allport (1954). Attitudes are referred to as psychological constructs that people hold and lends those people to either favor or not favor something or someone (Eagly \& Chaiken, 1993). Contact hypothesis suggests that contact to people who belong to a different group will decrease stigma and promote positive attitudes towards those people (Pettigrew, 1998). In line with the contact hypothesis, previous research found contact with a stigmatized group member was effective in reducing stigma (Corrigan, Morris, Michaels, Rafacz, \& Rüsch, 2012). Regarding pedophilia, Jahnke, Philipp, and Hoyer (2015b) studied the effectiveness of a very brief intervention (10 min), which provided indirect contact to a PWP via video, and their results suggest that content delivery via video by a PWP had an effect on a change in attitudes and consequently reducing stigma towards PWP. 
Further, research suggests that misconceptions and stereotypes about a stigmatized group can be challenged through educational strategies (Corrigan et al., 2012). Kleban and Jeglic (2012) showed that a psychoeducational intervention, combined with a discussion group, had a bigger impact on changing attitudes towards pedophilia than the psychoeducational intervention on its own.

To reduce negative attitudes and stigma surrounding pedophilia, research needs to understand what dimensions to target in anti-stigma interventions and what kind of interventions are effective. The present pilot study sought to provide further information on the anti-stigma intervention's effectiveness on different dimensions of social distance towards PWP. Moreover, its purpose is to determine whether direct contact to a PWP, combined with education, would have a desirable effect in reducing social distance of students towards PWP.

In line with previous research, we hypothesize that students at the University of Groningen will endorse punitive attitudes toward PWP (Jahnke, Imhoff, \& Hoyer, 2015a).

We also predict that students attending a lecture ("Talking about pedophilia") presenting accurate information about PWP and providing direct contact to a PWP will demonstrate changes in perception of PWP after the lecture. Further, we hypothesize that students' attitudes towards PWP regarding dangerousness, deviance, intentionality, and punitive attitudes will be less negative after the intervention than before the intervention. Finally, we hypothesize that perceived dangerousness, intentionality, and deviance will predict punitive attitudes.

\section{Method}

\section{Participants}

Two-hundred and two students from the University of Groningen took part in this pilot study. Thirty-one participants were excluded from the analysis because they either only filled in the first or the second questionnaire or because there were errors in their personalized code leading to the inability to match their pre and post questionnaires. Additionally, participants who classified as extreme outliers (exceeding 1.5 SD, $n=9$ ) were excluded from further analyses. The final sample consisted of 162 participants $(N=162)$, of which 131 were female (80.9\%), 29 male (17.9\%), and two that identified as other $(1.2 \%)$. Their age ranged from 18 to 29 years with a mean age of $M=21.25$ and a standard deviation of $S D=$ 2.18. Post hoc power analysis (using G*Power; Erdfelder, Faul, \& Buchner, 1996) for Wilcoxon-Signed-Rank-Test (one sample) with a given effect size $d=0.8$, alpha $=0.05$, and the sample size of $N=162$ revealed a power of $1-\beta=1$. The sample size, therefore, was sufficient for large effect sizes.
Participants were made aware of a lecture ("Talking about Pedophilia") two weeks in advance. The psychology study association of the University of Groningen (VIP) advertised the lecture online via Facebook. Also, there were posters and flyers hung around the buildings of the University. Only students of the University of Groningen were allowed to attend. Attending the lecture was free of charge, and participants received no incentive to participate.

\section{Ethical Considerations}

The Ethics Committee of Psychology (ECP) of the University of Groningen approved the present pilot study. Participants were informed about key aspects of the pilot study (e.g., anonymity, data handling) and provided written informed consent. Measures were taken to maintain the PWP (Gabriel's) safety, e.g., he used a pseudonym throughout the pilot study so that his real identity could be protected. Additionally, any kind of recording was prohibited during the lecture. Security personnel were informed of the lecture and were on standby, which ensured that Gabriel felt safe enough to speak.

\section{Material}

A PowerPoint presentation was used for the lecture. The slides of the presentation are available upon request. The intervention was not recorded to ensure the privacy of the guest speaker. Participants were also provided with a self-report demographics questionnaire before the lecture, which contained questions about their personal experiences with child sexual abuse and professional working experience with CSOs and PWP.

The 'Stigma and Punitive Attitudes Toward Pedophiles Scale' (Imhoff, 2015) was administered before and after the lecture. This three-dimensional questionnaire measures attitudes toward PWP on dangerousness, intentionality, and deviance, which have all been suggested critical dimensions to explain the social rejection of individuals with mental disorders (Feldman \& Crandall, 2007). This questionnaire consists of 30 items in total, which were rated on a 7-point Likert scale ranging from $1=$ strongly disagree to $7=$ strongly agree . Participant scores on each of the sub-scales were calculated using Imhoff's (2015) scoring procedure.

Finally, at the end of the lecture, a self-evaluation was obtained. Participants were asked what caused their attitude change (provided that attitude change happened): the lecture, meeting the PWP, or both.

\section{Study Design and Procedure}

A one-group pre-test post-test design was used. Participants gathered for the presentation in a lecture hall of the University of Groningen. Participants were asked to turn off their phones or any other electronic devices that can be used for recording. 
While entering the lecture hall, the students were reminded again that any kind of recording is prohibited, and a violation will lead to their exclusion of the presentation. Participants were informed that the pilot study's goal was to learn more about people's opinions on the topic of pedophilia. Subsequently, participants filled out the informed consent forms, as well as the first self-report questionnaire. Each participant created a personalized code to anonymize the data and match the pre-test responses to the post-test responses. Participants folded their answers and placed them in envelopes. The envelopes were collected, and the lecture started. Participants heard about pedophilia, pedophilic offenders, non-pedophilic child sex offenders, and the media's influence in forming and increasing misconceptions about pedophilia. The lecture included theories about the motivation of child sexual abuse, the difference between child sex offenders and PWP, the DSM-5 definition of pedophilic disorder, statistics about media representations of child sex offenses, dynamic risk factors of child sex offending, and a brief explanation of a prevention program called "Kein Täter warden ("Don't offend"). The focus of the intervention was the distinction between child sex offending and the concept of pedophilia. The research team together came up with lecture and one of the researchers delivered the lecture. The lecture took $45 \mathrm{~min}$ and was followed by a 15 -min break where students could leave the lecture hall. Upon reentering the lecture hall, students were again asked to show a turned off mobile phone. After the break, 34-year old Gabriel Levi (pseudonym) from the Netherlands provided a 50-min presentation about his experience being a PWP. He was approached via his website and gladly accepted the invitation to participate in the present pilot study. Before the pilot study, the lecture's content was discussed, and agreement on specific topics was reached. The lecture given by Gabriel Levi entailed information on his childhood, the realization of his sexual attraction, his struggles to incorporate being a PWP into his identity, his attempts to find appropriate coping strategies, and his overall experiences. After his talk, the participants were allowed to ask questions about both parts of the lecture for $30 \mathrm{~min}$. After the questions, participants had approximately $10 \mathrm{~min}$ to fill out the second questionnaire. The participants were asked to stay in their seats until all questionnaires were collected. In the meantime, Gabriel left the lecture hall. After the $10 \mathrm{~min}$ passed, participants were thanked for participating and dismissed.

\section{Statistical Analysis}

Descriptive statistics will be reported on the following variables of interest: dangerousness, intentionality, deviance, and punitive attitudes towards PWP. Further, assumptions will be tested.
Subsequently, a Wilcoxon signed-rank test will be used to identify whether students' attitudes regarding perceived dangerousness, intentionality, deviance, and punitive attitudes have changed after the intervention using JASP (JASP Team, 2019). Further, a one-sample Wilcoxon signed-rank test will determine whether students' scores on perceived punitive attitudes significantly differ from the lowest point of the scale using JASP (JASP Team, 2019).

The next step will investigate whether perceived dangerousness, intentionality, and deviance can predict variance in punitive attitudes. To correct for multiple testing, a Benjamini Hochberg correction was applied to all $p$-values (Benjamini \& Hochberg, 1995) using R (R Core Team, 2013).

\section{Thematic Analysis}

Data Collection and Analysis In the second questionnaire, the last question asked participants to elaborate on their thoughts about the lecture and their attitude change (provided that attitude change happened). The idea was to give the participants a chance to comment on the lecture, the guest lecturer, or any other topic they wanted to voice. No hypothesis was established before the data collection; thus an inductive approach was used. Further, the explicit content of the data was analyzed, therefore using a semantic approach. A thematic analysis was conducted following Braun and Clarke's 6 step model (Braun, Clarke, Hayfield, \& Terry, 2019). First, participants' responses were transcribed. Second, initial codes were created, and the data was coded systematically across the entire data set. Subsequently, participants' responses were coded into meaningful categories, reflecting the data. Third, initial codes were collated into potential themes, created by the researchers. Participants' responses were classified into the categories and counted to identify the frequency of those categories to make it easier to make sense of the data. Fourth, the themes were revised to ensure the initial codes reflect the themes by taking a step back and rereading the data. Fifth, names and descriptions for the themes were generated. Sixth, quotations to support each category were selected across the entire data set.

\section{Results}

\section{Quantitative Analysis}

Preliminary Analyses Four participants indicated that they had been a victim of child sexual abuse $(2.5 \%)$. Forty-six participants declared that they knew a victim of child sexual abuse (28.4\%). Nineteen participants specified that someone in their family had been a victim of child sexual abuse (11.7\%). Nineteen participants stated that they knew a perpetrator of child sexual abuse (11.7\%). Seven participants specified that 
they had worked in a professional capacity with child sexual abuse victims (4.3\%). Two participants indicated that they had worked in a professional capacity with PWP (1.2\%).

Furthermore, the evaluation of the lecture showed that most participants thought that both caused attitude change, the lecture and meeting the PWP $(n=126,77.8 \%)$, followed by meeting the PWP $(n=26,16 \%)$, and lastly, the lecture alone $(n=1,0.6 \%)$.

Table 1 depicts the means and standard deviations (preand post-measure) of the stigma scales and punitive attitudes.

Endorsement of the dangerousness scale in the pre-measure indicated that most participants perceived a link between pedophilia and child sexual abuse.

The lowest endorsement in the pre-measure was found in the intentionality scale. Median scores of four of the six items are equal to the lowest possible score $(1=$ strongly disagree $)$. Thus, most students strongly believed that PWP do not choose to be sexually attracted to prepubescent children. Only two items of the intentionality scale scored a lot higher. The median of item 10 ("Pedophilia is a disposition that you cannot do anything about") was $M d n=4$ (1.94; neither disagree nor agree), and the median of item 7 ("If someone is pedophilic, there is nothing he can do about it") was $M d n=5$ (1.91; slightly disagree).

Of all scales assessed, deviance was found to be endorsed the strongest in the pre-measure. Medians of all items of the deviance scale were above the midpoint of the scale $(4=n e i-$ ther disagree nor agree), except for item 15 ("Pedophiles are normal people with an infrequent sexual orientation", $M d n=3$ (1.70)). This indicates that most participants perceived individuals who are sexually attracted to children as mentally ill.

Spearman's correlation analysis was conducted to provide additional information on possible associations between dangerousness, intentionality, deviance, punitive attitudes, and personal experiences (see Table 2). All three stigma dimensions were positively correlated to each other as well as to punitive attitudes. In line with Feldman and Crandall (2007) and Imhoff (2015), the correlation between punitive attitudes and dangerousness was found to be the strongest. Contrasting Feldman and Crandall (2007) and Imhoff (2015), it was followed by the association between punitive attitude and

Table 1 Means and Standard Deviations, Pre- and Post-measure

\begin{tabular}{|c|c|c|c|c|}
\hline \multirow[t]{2}{*}{ Scale } & \multicolumn{2}{|c|}{ Pre-measure } & \multicolumn{2}{|c|}{ Post-measure } \\
\hline & $M$ & $S D$ & $M$ & $S D$ \\
\hline Dangerousness & 3.98 & 0.93 & 2.38 & 0.72 \\
\hline Intentionality & 2.41 & 0.83 & 2.00 & 0.77 \\
\hline Deviance & 4.64 & 1.08 & 3.28 & 1.05 \\
\hline Punitive Attitude & 2.93 & 0.61 & 2.30 & 0.50 \\
\hline
\end{tabular}

Note. $N=162$ intentionality, and lastly, punitive attitude and deviance. Also, spearman's correlations between knowing a perpetrator of CSA, knowing a victim of CSA, and having a victim of CSA in the family were all found to be significant.

Assumptions Several procedures to test assumptions were performed. Except for the scale of dangerousness, all other scales showed violations of the normality assumption in the ShapiroWilk test; dangerousness ( $W=0.983, p=.040)$, intentionality $(W=0.978, p=.011)$, deviance $(W=0.964, p<.001)$, punitive attitudes $(W=0.971, p=.002)$. Even though the student's $\mathrm{t}$ test appears to be relatively robust to normality violations (Green \& Salkind, 2008), the Shapiro-Wilks test results indicate a severe violation of normality, which is why the Wilcoxon signed-rank test was selected. Subsequently, difference scores for all variables were visually assessed and showed sufficient equality, except for deviance, where the assumption of equal variance of difference was violated. The assumption of linearity was severely violated, even after transformations were performed. Due to this violation, the regression analysis was not performed since the predictions are likely to be seriously flawed.

Main Analyses Results supported the first hypothesis that (psychology) students from the University of Groningen hold punitive attitudes toward PWP. A Wilcoxon signed-rank test for each of the 13 items of the punitive attitude scale was conducted and can be found in Table 3, as well as medians and standard deviations. As seen in Table 3, at the premeasure level, the median of all 13 items scored significantly above the lowest point of the scale, and not a single item was strongly uniformly rejected. Although one item was lesser engaged than others (item 30 ("Pedophiles should be sentenced to death as a deterrence"), it was still not uniformly rejected.

To test the second hypothesis, whether the anti-stigma intervention affected perceived dangerousness, intentionality, deviance, and punitive attitudes, a Wilcoxon signed-rank test was conducted. As shown in Table 4, the second hypothesis was confirmed. There was a significant difference in the preand post-measure scores for dangerousness, intentionality, deviance, and punitive attitudes. Students showed strongly changed attitudes towards PWP on all scales after the intervention. The data found support for the hypothesis that students' negative attitudes towards PWP were less negative after the intervention. The biggest change in attitude was observed in the scale of dangerousness, which can be interpreted as a large effect (Benesty, Chen, Huang, \& Cohen, 2009). Except for the effect of attitude change in intentionality, which was small in effect size, all other effect sizes can be interpreted as large. Medians, standard deviations (pre- and post-measure), and the Wilcoxon signed-rank test results of all individual items can be found in Table 5 . 
Table 2 Spearman's Intercorrelations (at pre-test level)
Items

\begin{tabular}{lllllllll}
\hline 1. & 2. & 3. & 4. & 5. & 6. & 7. & 8. & 9.
\end{tabular}

1. Dangerousness

2. Intentionality

3. Deviance

4. Punitive Attitudes

5. Gender

6. Age

7. Family victim

8. Know perpetrator

9. Know Victim

10. Victim
$.48^{* *}$

$.50^{* *} .39^{* *}$

$.57^{* *} \quad .37^{* *} \quad .46^{* *}$

$\begin{array}{llll}.19^{*} & .16 & .11 & .12\end{array}$

$\begin{array}{lll}-.07 & -.11 \quad .13\end{array}$

$\begin{array}{lll}.10 & .07 & .05\end{array}$

$.14 \quad .14 \quad .07$

$\begin{array}{lll}-.00 & .01 & -.03\end{array}$

$\begin{array}{lll}.02 & -.05 & .81\end{array}$

$\begin{array}{lllll}-.06 & -.21^{*} & - & & \\ .10 & .15 & .10 & - & \\ .06 & .07 & -.10 & .44^{* *} & - \\ .03 & .19^{*} & .03 & .46^{* *} & .44^{* *} \\ .02 & .07 & -.21 & .25^{* *} & .24\end{array}$

0.12

Note: $N=162$, 7. Family victim $=$ Has anyone in your family ever been the victim of child sexual abuse?. 8 . Known perpetrator $=$ Do you personally know anyone who has sexually abused a child?, 9. Known Victim = Do you personally know anyone who has been a victim of child sexual abuse?, ${ }^{*} p<.05,{ }^{* *} \mathrm{p}<.001$

\section{Thematic Analysis}

Results Four main themes were found providing further insight about what students thought about the lecture. Namely, meeting a PWP $(n=35,43.2 \%)$, interest in the topic of pedophilia $(n=15,18.5 \%)$, humanization $(n=8,9.9 \%)$, and gratitude $(n=9,11.1 \%)$.

Meeting a pedophile Thirty-five participants (43.2\%) commented on meeting the PWP and how they felt about that. Comments on meeting the PWP were solely positive, and participants acknowledged that meeting a PWP who discloses his attraction to children is rare. In accordance with previous research results (Corrigan et al., 2012), meeting a stigmatized individual can result in attitude change, and the comments regarding meeting the PWP are supportive of that.

"It was an eye-opening experience to hear the perspective of a pedophile!" - Participant 157.

Interest in the topic of pedophilia Fifteen participants (18.5\%) indicated a great deal of interest in the topic of pedophilia. Participants commented that their knowledge of pedophilia

Table 3 Punitive Attitude Scale, Medians, Standard deviations, One sample Wilcoxon signed-rank test

\begin{tabular}{|c|c|c|c|c|c|c|c|c|c|}
\hline \multirow[t]{2}{*}{ No } & \multirow[t]{2}{*}{ Items } & \multicolumn{4}{|l|}{ Pre-measure } & \multicolumn{4}{|c|}{ Post- measure } \\
\hline & & $M d n(S D)$ & $Z$ & $p$ & $\delta$ & $M d n(S D)$ & $Z$ & $p$ & $\delta$ \\
\hline 18 & Pedophiles should be preemptively taken into custody. & $2.00(1.39)$ & -3.29 & .001 & 0.37 & $1.00(0.82)$ & -8.45 & 1.000 & 1.06 \\
\hline 19 & One should not condemn pedophiles too harshly. ${ }^{\mathrm{R}}$ & $3.00(1.43)$ & 9.04 & $<.001$ & 1.16 & $2.00(1.44)$ & -4.01 & $<.001$ & 0.46 \\
\hline 20 & Pedophiles should be castrated. & $1.00(1.28)$ & -1.63 & 0.789 & 0.18 & $1.00(0.62)$ & -9.89 & 1.000 & 1.31 \\
\hline 21 & Known pedophiles should be sentenced for life as deterrence. & $2.00(1.22)$ & -1.28 & 0.035 & 0.14 & $1.00(0.77)$ & -9.65 & 1.000 & 1.27 \\
\hline 22 & Pedophiles should be allowed to work with children. ${ }^{\mathrm{R}}$ & $6.00(1.41)$ & 11.07 & $<.001$ & 1.58 & $5.00(1.42)$ & 10.69 & $<.001$ & 1.48 \\
\hline 23 & $\begin{array}{l}\text { Citizens should have a right to get informed if pedophiles } \\
\text { move to their neighborhood. }\end{array}$ & $3.00(1.51)$ & 7.84 & $<.001$ & 0.97 & $2.00(1.33)$ & -1.79 & 0.130 & 0.20 \\
\hline 24 & Pedophiles should be forced to undergo therapy. & $5.00(1.56)$ & 10.44 & $<.001$ & 1.42 & $3.00(1.57)$ & 7.40 & $<.001$ & 0.90 \\
\hline 25 & $\begin{array}{l}\text { If all other means fail, it should be legal in exceptional } \\
\text { cases to torture pedophiles. }\end{array}$ & $1.00(0.65)$ & -10.21 & 1.000 & 1.38 & $1.00(0.69)$ & -9.75 & 1.000 & 1.29 \\
\hline 26 & $\begin{array}{l}\text { Pedophiles should experience leniency when dealing } \\
\text { with the legal system. }\end{array}$ & $4.00(1.29)$ & 11.14 & $<.001$ & 1.58 & $4.00(1.41)$ & 11.11 & $<.001$ & 1.5 \\
\hline 27 & $\begin{array}{l}\text { There should be a website listing pedophiles with name, } \\
\text { photo, and address. }\end{array}$ & $1.00(0.89)$ & -6.26 & 1.000 & 0.74 & $1.00(0.81)$ & -7.48 & 1.000 & 0.91 \\
\hline 28 & Pedophiles should be chemically castrated. & $1.00(1.32)$ & -2.56 & 0.968 & 0.29 & $1.00(0.85)$ & -8.87 & 1.000 & 1.13 \\
\hline 29 & $\begin{array}{l}\text { The privacy of pedophiles is more important than information } \\
\text { and safety needs of the public. }{ }^{R}\end{array}$ & $4.00(1.32)$ & 10.33 & $<.001$ & 1.40 & $4.00(1.41)$ & 9.57 & $<.001$ & 1.25 \\
\hline 30 & Known pedophiles should be sentenced to death as deterrence & $1.00(0.62)$ & -10.14 & 1.000 & 1.36 & $1.00(0.39)$ & -11.69 & 1.000 & 1.71 \\
\hline
\end{tabular}

Note: $N=162$, For all tests, the alternative hypothesis specifies that the median is greater than 2 (disagree); ${ }^{\mathrm{R}} \mathrm{Rev}$ 
Table 4 Descriptive statistics, Wilcoxon signed-rank test, Cohen's d

\begin{tabular}{|c|c|c|c|c|c|}
\hline \multirow[t]{2}{*}{ Dimensions } & \multirow{2}{*}{$\begin{array}{l}\text { Pre- } \\
\text { measure } \\
M d n(S D)\end{array}$} & \multirow{2}{*}{$\begin{array}{l}\text { Post- } \\
\text { measure } \\
M d n(S D)\end{array}$} & \multicolumn{3}{|c|}{ Wilcoxon signed-rank test } \\
\hline & & & $\Delta M d n(S D)$ & $Z$ & $\delta$ \\
\hline Dangerousness & $4.00(0.92)$ & $2.40(0.73)$ & $-1.60(0.84)$ & $-10.79^{*}$ & 1.49 \\
\hline Intentionality & $2.33(0.83)$ & $1.83(0.77)$ & $-0.50(1.10)$ & $-6.43^{*}$ & 0.76 \\
\hline Deviance & $4.83(1.08)$ & $3.16(1.05)$ & $-1.67(1.05)$ & $-10.66^{*}$ & 1.47 \\
\hline Punitive Attitudes & $2.85(0.61)$ & $2.23(0.50)$ & $-0.62(0.54)$ & $-10.29^{*}$ & 1.39 \\
\hline
\end{tabular}

Note. $N=162,{ }^{*} p<.001$ was sparse beforehand and that they would like to have learned even more about the topic.

"This was really interesting and eye-opening." Participant 29.

Gratitude Nine participants (11.1\%) expressed gratitude towards the PWP and the lecturer. They acknowledged that it must have been hard to disclose a sexual attraction to children in front of an audience and appreciated the guest lecturers' bravery. Further, they thanked him for the opportunity to learn about pedophilia from a different perspective.

"Both of the lectures were highly informative, and I am very glad I came to listen. (...) Thanks a lot for opening my eyes and fighting stigma." - Participant 162.
PWP as normal human beings Eight participants (9.9\%) indicated in their statements that they now see PWP as normal human beings. It could indicate that at least some participants in the present pilot study did not perceive PWP as human beings before the lecture.

"Pedophiles have been humanized to me."- Participant 117.

\section{Discussion}

The present pilot study sought to determine whether an educational intervention combined with direct contact to a PWP would reduce negative attitudes of psychology students at the University of Groningen toward PWP. Students' attitudes

Table 5 Items of all scales, Medians, Wilcoxon signed-rank test, Cohen's d

\begin{tabular}{|c|c|c|c|c|c|c|c|}
\hline \multirow[t]{2}{*}{ Scale } & \multirow[t]{2}{*}{ No } & \multirow[t]{2}{*}{ Items } & \multirow{2}{*}{$\begin{array}{l}\text { Pre-measure } \\
M d n(S D)\end{array}$} & \multirow{2}{*}{$\begin{array}{l}\text { Post-measure } \\
M d n(S D)\end{array}$} & \multicolumn{3}{|c|}{ Wilcoxon signed-rank test } \\
\hline & & & & & $Z$ & $p$ & $\delta$ \\
\hline \multirow[t]{5}{*}{ Dangerousness } & 1 & Pedophiles are dangerous for children. & $6.00(1.18)$ & $3.00(1.43)$ & -10.41 & $<.001$ & 1.36 \\
\hline & 2 & Pedophiles are perverse sex offenders. & $4.00(1.79)$ & $1.00(0.82)$ & -10.32 & $<.001$ & 1.34 \\
\hline & 3 & $\begin{array}{l}\text { There exists no strong relationship between pedophilia and } \\
\text { sexual abuse of children. }{ }^{R}\end{array}$ & $5.00(1.35)$ & $3.00(1.62)$ & -8.00 & $<.001$ & 0.96 \\
\hline & 4 & Many pedophiles never have any sexual contact with a child. ${ }^{R}$ & $3.00(1.37)$ & $2.00(1.22)$ & -2.63 & .008 & 0.29 \\
\hline & 5 & Pedophilia sooner or later always leads to child sexual abuse. & $2.00(1.45)$ & $1.00(0.93)$ & -8.65 & $<.001$ & 1.06 \\
\hline \multirow[t]{6}{*}{ Intentionality } & 6 & Pedophilia is something that you choose for yourself. & $1.00(1.03)$ & $1.00(0.69)$ & -4.16 & $<.001$ & 0.46 \\
\hline & 7 & If someone is pedophilic, there is nothing he can do about it. ${ }^{R}$ & $5.00(1.92)$ & $3.00(2.08)$ & -5.20 & $<.001$ & 0.59 \\
\hline & 8 & If someone is pedophilic, it is his own fault. & $1.00(0.98)$ & $1.00(0.79)$ & -4.34 & $<.001$ & 0.48 \\
\hline & 9 & People can decide whether they are pedophilic or not. & $1.00(0.91)$ & $1.00(1.01)$ & -3.78 & $<.001$ & 0.42 \\
\hline & 10 & Pedophilia is a disposition that you cannot do anything about. ${ }^{R}$ & $4.00(1.94)$ & $2.00(2.12)$ & -4.07 & $<.001$ & 0.45 \\
\hline & 11 & $\begin{array}{l}\text { People with a pedophilic orientation have consciously } \\
\text { decided for this orientation. }\end{array}$ & $1.00(1.03)$ & $1.00(0.86)$ & -4.63 & $<.001$ & 0.52 \\
\hline \multirow[t]{6}{*}{ Deviance } & 12 & Pedophilia does not require treatment. ${ }^{R}$ & $7.00(1.03)$ & $5.00(1.51)$ & -8.22 & $<.001$ & 0.99 \\
\hline & 13 & Pedophilia is not pathological. ${ }^{\mathrm{R}}$ & $6.00(1.36)$ & $4.00(1.67)$ & -8.01 & $<.001$ & 0.96 \\
\hline & 14 & Pedophilia is a mental disorder, like for example schizophrenia. & $5.00(1.69)$ & $3.00(1.66)$ & -6.59 & $<.001$ & 0.76 \\
\hline & 15 & Pedophiles are normal people with an infrequent sexual orientation. ${ }^{R}$ & $3.00(1.70)$ & $2.00(1.30)$ & -7.89 & $<.001$ & 0.94 \\
\hline & 16 & Pedophiles are sick. & $4.00(1.71)$ & $2.00(1.35)$ & -10.13 & $<.001$ & 1.31 \\
\hline & 17 & $\begin{array}{l}\text { Someone who is pedophilic but never sexually abuses a child is } \\
\text { not mentally ill. }{ }^{R}\end{array}$ & $5.00(1.83)$ & $3.00(1.79)$ & -7.69 & $<.001$ & 0.91 \\
\hline
\end{tabular}


regarding perceived dangerousness, intentionality, deviance, and punitive attitudes were assessed. Attitudes of all scales changed significantly after the intervention, which supports the hypothesis. Obtained results are in line with previous research and provide further evidence for the effectiveness of educational interventions in reducing stigma toward PWP (Jahnke, Imhoff, \& Hoyer, 2015a). Additionally, results suggest that psychology students of the University of Groningen hold punitive attitudes towards PWP.

High endorsement of perceived dangerousness (e.g., "Pedophiles are dangerous for children") of PWP indicates that the majority of students linked pedophilia to child sexual abuse before the lecture. As argued, the merging of PWP and child sex offenders (CSOs) leads to increased perceptions of dangerousness of PWP (Harper et al., 2018). Attitude change regarding the perceived dangerousness of PWP was the highest of all scales. It is reasonable to assume that this conflation plays a role in observed attitude change since the intervention explicitly explained the differences between CSOs and PWP, hence decreasing perceived dangerousness after the intervention. Although a lot less engaged after the intervention, perceived dangerousness was still well endorsed, indicating that students still perceived pedophilia somewhat connected to child sexual abuse. Conclusions about whether the perceived dangerousness observed after the intervention stems from the actual dangerousness imposed by PWP or the negative stigma surrounding pedophilia cannot be drawn.

Compared to the other scales, perceived intentionality was the least endorsed both before and after the intervention, indicating that students believed that PWP do not choose to be attracted to minors (e.g., "Pedophilia is something that you choose for yourself'). The observed attitude in perceived intentionality changed significantly. It is assumed that because of prior knowledge of psychological disorders, psychology students knew that a psychological disorder is generally not self-chosen. Other samples, not consisting of psychology students, would presumably show a different endorsement of perceived intentionality. Also, students thinking about the sexual attraction to children as a sexual orientation could have been aware of the assumption that sexual orientation is nothing people can change (Seto, 2012). However, in the study of Wurtele (2018), testing the effectiveness of a classroom intervention to reduce misconceptions toward child sex offenses, psychology students at the University of Colorado at Colorado Springs initially believed that persons with pedophilia chose their sexual attraction or can change it. One reason for these contrary findings could be the nationality of the sample. Jahnke, Imhoff, and Hoyer (2015a) found higher resentment against PWP in an American sample than a German sample. However, the present pilot study was not conducted in Germany but the Netherlands. A definite conclusion about the low scores on intentionality in both the pre- and post-measure cannot be drawn.
Students' scores on deviance were the highest compared to the other scales both before and after the intervention (e.g., "Pedophilia is a mental disorder, like for example, schizophrenia"). Before the intervention, most students perceived PWP as psychologically deviant. Observed attitude change in deviance was found to be very high. After the intervention, the majority of students slightly disagreed with persons with pedophilia being psychologically deviant. Thus, after the intervention, more students believed that a sole sexual attraction to children does not necessarily imply a mental disorder. During the intervention, the DSM-5 definition of the pedophilic disorder was explained at length. Students learned that to be diagnosed as suffering from pedophilic disorder, more diagnostic criteria have to be fulfilled than just being sexually attracted to prepubescent children. Thus, students learned that a PWP does not necessarily suffer from a mental disorder. Further, students and the guest lecturer discussed the concept of pedophilia being a sexual orientation. It is reasonable to assume that accurate factual knowledge provided in the intervention, in addition to the impression of the guest lecturer, led students to perceive pedophilia as less psychologically deviant after the lecture. The students interacted respectfully with the guest lecturer, and it could be presumed that students got the impression that he is not deviant except for his sexual attraction.

In addition to testing the effect of an anti-stigma intervention, we also hypothesized that (psychology) students at the University of Groningen hold punitive attitudes toward PWP. Results revealed that students, before the intervention, held punitive attitudes towards PWP, supporting the hypothesis. These findings are in line with previous research suggesting that people hold punitive attitudes towards PWP even if there is no mention of any committed crime (Jahnke, 2018a). We found that students did not uniformly firmly reject punishment, neither prior nor after the intervention. Almost half of the punitive attitude scale items were either only slightly disagreed to, agreed to, or answered as uncertain. Students were asked to what extent they want to punish PWP, and there was no mention of any committed crimes. Therefore, the decision to punish PWP was solely based on their sexual attraction, not their actual behavior. Furthermore, a significant attitude change was observed regarding punitive attitudes after the intervention. On average, instead of slightly disagreeing with punishment, after the intervention, students disagreed with punishment. Although the intervention succeeded in diminishing punitive attitudes, there was still no strong uniform rejection of punishment after the intervention. It is assumed that students were able to differentiate between PWP and CSOs after the intervention since the distinction between the constructs was one central point in the educational intervention and was explained at length. One reason for the observation of punitive attitudes after the intervention could be social desirability. Research by Imhoff 
(2015) suggested that holding punitive attitudes toward PWP is socially desirable. Also, PWP are highly stigmatized, and social distance towards PWP is greater than to any other mental illness (Feldman \& Crandall, 2007). Future research should investigate whether students still want to punish PWP after learning the differentiation between PWP and CSOs because they want to act socially desirable, do not understand the differentiation, want to reach social distance, or else.

We also predicted that punitive attitudes could be explained by perceived dangerousness, intentionality, and deviance. During the data analysis, it became apparent that a prediction is not possible with the current data since assumptions that ensure accurate predictions were severely violated. Therefore, prediction analysis was not performed and cannot be discussed.

Unlike previous research analyzing anti-stigma interventions' effectiveness, the present pilot study was the first to provide direct contact to a PWP as a part of an anti-stigma intervention. Stigma research suggests that direct contact yields the strongest effects compared to other anti-stigma interventions (Corrigan et al., 2012). It has been shown that even indirect contact to a PWP (e.g., video material showing a PWP talking about pedophilia) was able to diminish punitive attitudes (Jahnke, Philipp, \& Hoyer, 2015b). Although the present pilot study did not compare different anti-stigma interventions, substantial differences between pre- and post-measures and large effect sizes were found. Whether direct contact to a PWP is more effective than indirect contact in terms of reducing stigma should be researched further. For example, it would be beneficial to investigate if there are differences between direct and indirect contact as well as if an educational lecture alone is as effective without the element of (direct/indirect) contact (see Limitations and Future Research for more details).

Jahnke et al. (2015a, b) referred to indirect contact (e.g., video) as being more feasible than direct contact, especially in terms of effort and safety for the PWP. Planning and conducting the present pilot study demanded a certain amount of effort, which could have been drastically reduced by using video content. However, no major troubles (like safety issues or assaults) have arisen while planning or conducting it. The guest lecturer's safety was an absolute priority and was assured through careful planning and security personnel. Students were obliged to be respectful towards the guest lecturer, and precautions were taken to make sure there were no records of the intervention. The lack of research on comparing an indirect contact intervention to a direct contact intervention makes it impossible to determine which intervention is more effective. Future research comparing direct contact to a PWP vs. indirect contact to a PWP and their effectiveness of stigma is needed to make the decision.

The thematic analysis revealed more insights into what participants wanted to comment on after the lecture and meeting the PWP. Participants exclusively stated positive impressions of the guest lecturer. However, not all participants commented on their impressions of the lecture and the PWP. It is therefore difficult to say that nobody had a negative impression of the guest lecturer. Thus, it is difficult to make assumptions and when conducting future research, it is important to be mindful of asking participants about their impressions both potentially positive or negative of the PWP.

Further, several participants pointed out their great interest in the topic of pedophilia and their lack of knowledge about pedophilia. Additionally, when advertised, the lecture was booked up entirely in just a few days. There was great interest in the topic of pedophilia among psychology students, which could be indicative of the fact that students are interested in attending more lectures and classes on the topic of pedophilia. The effectiveness of reducing stigma towards PWP of providing psychology students with more training options on pedophilia as early as during their studies should be assessed in future research.

The participants also showed appreciation and gratitude for the opportunity to understand the point of view of a PWP. Further, several participants commented on perceiving the guest lecturer as a "normal human being" after attending the lecture. Moral Disengagement theory (Bandura, Barbaranelli, Caprara, \& Pastorelli, 1996) theorizes that people dehumanize perpetrators of CSA (and PWP since they commonly conflate both) to create social distance. One could assume that several participants taking part in the present pilot study dehumanized PWP before the intervention. Through meeting the PWP, those participants were under the impression that the guest lecturer is as a human being as they are, probably leading them to acknowledge that PWP are human, too.

\section{Limitations and Future Research}

Single group studies like the present one lack external validity due to the non-consideration of control groups. Therefore, observed changes could also be attributed to other factors unrelated to the intervention, which is the major limitation of this pilot study. The pre-measure served as an explicit comparison where attitudes of individual subjects were compared before and after the intervention. However, changes in prepost measures cannot be interpreted carelessly.

Although the present study was the very first to investigate the effects of personal contact with a PWP, its results cannot be directly ascribed to it. The personal contact was inseparably combined with the educational lecture. One cannot distinguish which part of the intervention evoked the observed change in attitudes or if the change was due to an interaction of both. This must be kept in mind when interpreting the results of this present pilot study. Though the vast majority of the students did attribute their attitude change to the combination of both the lecture and meeting the PWP, strongly pointing to an interaction, future research should investigate this further. 
By additionally adding the following control groups, future research could address all the mentioned major limitations of the present pilot study: experiencing (1) no intervention at all, (2) a lecture on the topic of pedophilia alone, (3) exclusively having personal contact with a PWP and (4) attending both a lecture and having contact with a PWP.

The sample itself might constitute an additional minor limitation of this pilot study. This is due to two reasons. First, the students who participated in this pilot study actively chose to do so. Therefore, they may have been more open to or interested in the topic of pedophilia as well as to the changing their attitude towards this topic. Thus, the sample was self-selected and may have slightly biased the observed results. Second, the large gender disparity of this pilot study may have distorted the observed results. This limited population validity may reduce the ability to extrapolate the observed results to the entire population. It cannot be ruled out entirely that the large gender disparity does not bias the result. However, gender disparity among psychology students is quite common, with a vast majority of psychological studies having disproportionately more females than males (Cope, Michalski, \& Fowler, 2016). Future research should consider obtaining different samples, e.g., mandating students to attend as part of their studies and focusing on a more equalized population to address gender effects on attitudes toward pedophilia.

Furthermore, the present pilot study relied on self-report measures, which are vulnerable to social desirability bias (Fisher \& Katz, 2000). Considering Imhoff's (2015) findings, this could have led students to answer harsher than they would because holding punitive attitudes towards PWP was found socially desirable. Also, the present pilot study solely assessed explicit attitude change. Therefore, conclusions about implicit attitude changes or behavioral change as measures of the effectiveness of an anti-stigma intervention like the present one cannot be drawn. Furthermore, the intervention's educational part was presented by one of the researchers and so this could have resulted in a demand effect. Participants could have been aware of the underlying hypothesis, resulting in biased results.

Additional research is also needed to determine whether observed attitude change would alter after some time has passed. A follow-up questionnaire could be used to examine this question.

This pilot study also asked participants personal questions, for example, whether they had been a victim of sexual abuse or had known someone who had been, with the aim of understanding if this affected stigma toward PWP. However, we cannot draw any conclusions due to the small sample size $(n=4)$ of participants who disclosed being sexually abused or knowing someone who had been. Future research therefore is needed to investigate the relationship between victims of sexual abuse and their attitudes toward PWP.

\section{Implications}

The thematic analysis revealed that many students were very interested in the topic of pedophilia, and the lecture received very positive feedback in general. One could assume that other (psychology) students are also interested in learning more about this topic. Anti-stigma interventions targeting key groups (e.g., psychology students, psychotherapists, other health care providers) could be implemented in other Universities and beyond that. By educating future psychologists and psychotherapists about pedophilia and the consequences of stigma, it might be possible to reduce the stigma surrounding pedophilia to create a more understanding society.

Contemporary society needs to understand that isolating PWP is not reducing child sexual offending. The current strategy to deal with PWP might be socially desirable and motivated by the strict rejection of child abuse; however, it does not result in just that. Recognition of the adverse effects of stigma and the ultimate result of increasing dynamic risk factors for sexual offending needs to be established in order for society to accept that punishing PWP is not helping anyone. We argue that it is essential to be very precise in distinguishing between PWP and CSOs to avoid nourishing punitive attitudes towards PWP due to conceptual confusion. Research on stigma surrounding pedophilia is increasing, and it is not a blind spot anymore like Jahnke and Hoyer called it in Jahnke \& Hoyer, 2013. Increasing research interest on this issue is encouraging and should be supported, especially as stigma towards pedophilia is still present among research professionals.

\section{Conclusion}

Results of the present pilot study provide evidence for the effectiveness of an anti-stigma intervention combining education and direct contact to a PWP in reducing stigma towards PWP. After students were educated about pedophilia and met a PWP, their attitudes on perceived dangerousness, intentionality, deviance, and punitive attitudes strongly diminished. The present pilot study was the first to provide direct contact to a PWP, though combining it with an educational lecture about pedophilia to promote attitude change and ultimately decrease stigma towards PWP. Despite its limitations in part due to limited resources, with combining education and direct contact, the present pilot study uses an interesting approach to diminish negative attitudes towards PWP. Results of the present pilot study add to a growing field of research on reducing stigma surrounding pedophilia. Keeping in mind the adverse consequences stigma can have on the stigmatized individuals, antistigma interventions are necessary. Concerning pedophilia, anti-stigma interventions could be beneficial in ensuring a better life for PWP and ultimately reducing child sexual abuse. 
Contemporary society needs to rethink its strategy to approach PWP to reduce child sexual abuse, and anti-stigma interventions like the present one could be an effective way of doing so.

Funding The University of Groningen funded this pilot study.

Data Availability The datasets generated during and/or analyzed during the current pilot study are available from the corresponding author on reasonable request.

\section{Compliance with Ethical Standards}

Conflict of Interest The authors declare no conflicts of interest.

Ethics Approval This pilot study was performed in line with the principles of the Declaration of Helsinki. Approval was granted by the Ethics Committee of the University of Groningen.

Open Access This article is licensed under a Creative Commons Attribution 4.0 International License, which permits use, sharing, adaptation, distribution and reproduction in any medium or format, as long as you give appropriate credit to the original author(s) and the source, provide a link to the Creative Commons licence, and indicate if changes were made. The images or other third party material in this article are included in the article's Creative Commons licence, unless indicated otherwise in a credit line to the material. If material is not included in the article's Creative Commons licence and your intended use is not permitted by statutory regulation or exceeds the permitted use, you will need to obtain permission directly from the copyright holder. To view a copy of this licence, visit http://creativecommons.org/licenses/by/4.0/.

\section{References}

Allport, G. W. (1954). The nature of prejudice (p. 537). Reading, MA: Addison-Wesley.

American Psychiatric Association. (2013). Diagnostic and statistical manual of mental disorders, DSM-5 (5th ed.). Washington, DC: American Psychiatric Association.

B4U-ACT. (2011). Youth, suicidality, and seeking care. Retrieved from: https://www.b4uact.org/research/survey-results/youth-suicidalityand-seeking-care/

Bandura, A., Barbaranelli, C., Caprara, G. V., \& Pastorelli, C. (1996). Mechanisms of moral disengagement in the exercise of moral agency. Journal of Personality and Social Psychology, 71, 364-374.

Benesty, J., Chen, J., Huang, Y., \& Cohen, I. (2009). Pearson correlation coefficient. In Noise reduction in speech processing (pp. 37-40). Heidelberg: Springer. https://doi.org/10.1007/978-3-642-00296-0 5.

Benjamini, Y., \& Hochberg, Y. (1995). Controlling the false discovery rate: A practical and powerful approach to multiple testing. Journal of the Royal Statistical Society Series B, 57, 289-300.

Braun, V., Clarke, V., Hayfield, N., \& Terry, G. (2019). Thematic analysis. In Handbook of Research Methods in Health Social Sciences. Singapore: Springer. https://doi.org/10.1007/978-981-105251-4 103 .

Cash, B. M. (2016). Self-identifications, sexual development, and wellbeing in minor-attracted people: An exploratory study (Master's thesis). Ithaca, NY: Cornell University.

Cope, C., Michalski, D, S., \& Fowler, G, A. (2016). Graduate study in psychology 2017 Summary Report: Student demographics.
American Psychological Association, Education Directorate, Office of Graduate and Postgraduate Education \& Training. Retrieved from http://www.apa.org/education/grad/survey-data/ 2017-student-demographics.pdf.

Corrigan, P. W., Morris, S. B., Michaels, P. J., Rafacz, J. D., \& Rüsch, N. (2012). Challenging the public stigma of mental illness: A metaanalysis of outcome studies. Psychiatric Services, 63(10), 963-973.

Eagly, A. H., \& Chaiken, S. (1993). The psychology of attitudes. Orlando, FL: Harcourt Brace Jovanovich College.

Erdfelder, E., Faul, F., \& Buchner, A. (1996). GPOWER: A general power analysis program. Behavior Research Methods, Instruments \& Computers, 28(1), 1-11.

Feelgood, S., \& Hoyer, J. (2008). Child molester or paedophile? Sociolegal versus psychopathological classification of sexual offenders against children. Journal of Sexual Aggression, 14(1), 33 43.

Feldman, D. B., \& Crandall, C. S. (2007). Dimensions of mental illness stigma: What about mental illness causes social rejection? Journal of Social and Clinical Psychology, 26(2), 137-154.

Fisher, R. J., \& Katz, J. E. (2000). Social-desirability bias and the validity of self-reported values. Psychology \& Marketing, 17(2), 105-120.

Green, S. B., \& Salkind, N. J. (2008). Using SPSS for windows and macintosh: Analyzing and understanding data. Uppersaddle River: Prentice Hall.

Harper, C. A., \& Hogue, T. E. (2015). Measuring public perceptions of sex offenders: Reimagining the community attitudes toward sex offenders (CATSO) scale. Psychology, Crime and Law., 21(5), $452-470$.

Harper, C. A., \& Hogue, T. E. (2017). Press coverage as a heuristic guide for social decision-making about sexual offenders. Psychology, Crime and Law, 23(2), 118-134.

Harper, C. A., Bartels, R. M., \& Hogue, T. E. (2018). Reducing stigma and punitive attitudes toward pedophiles through narrative humanization. Sexual Abuse, Journal of Research and Treatment, 30(5), $533-555$.

Imhoff, R. (2015). Punitive attitudes against pedophiles or persons with sexual interest in children: Does the label matter? Archives of Sexual Behavior, 44(1), 35-44.

Imhoff, R., \& Jahnke, S. (2018). Determinants of punitive attitudes toward people with pedophilia: Dissecting effects of the label and intentionality ascriptions. Archives of Sexual Behavior, 47(2), $353-361$

Jahnke, S. (2018a). Emotions and cognitions associated with the stigma of nonoffending pedophilia: A vignette experiment. Archives of Sexual Behavior, 47, 363-373.

Jahnke, S. (2018b). The stigma of pedophilia: Clinical and forensic implications. European Psychologist, 23(2), 144-153.

Jahnke, S., \& Hoyer, J. (2013). Stigmatization of people with pedophilia: A blind spot in stigma research. International Journal of Sexual Health, 25(3), 169-184.

Jahnke, S., Imhoff, R., \& Hoyer, J. (2015a). Stigmatization of people with pedophilia: Two comparative surveys. Archives of Sexual Behavior, 44(1), 21-34.

Jahnke, S., Philipp, K., \& Hoyer, J. (2015b). Stigmatizing attitudes towards people with pedophilia and their malleability among psychotherapists in training. Child Abuse and Neglect, 40, 93-102.

JASP Team (2019). JASP (Version 0.9.2)[Computer software].Retrieved from https://jasp-stats.org/.

King, L., \& Roberts, J. (2017). The complexity of public attitudes toward sex crimes. Victims \& Offenders, 12(1), 71-89.

Kleban, H., \& Jeglic, E. (2012). Dispelling the myths: Can psychoeducation change public attitudes towards sex offenders? Journal of Sexual Aggression, 18(2), 179-193.

Koops, T., Turner, D., Jahnke, S., Märker, V., \& Briken, P. (2016). Stigmatisierung von menschen mit sexuellem Interesse an Kindern unter Sexualtherapeuten in Russland [stigmatization of people with 
a sexual interest in children among sex therapists in Russia]. Zeitschrift für Sexualforschung, 29, 131-146.

Kramer, R. (2011). The DSM and the stigmatization of people who are attracted to minors (Pedophilia, minor-attracted persons, and the DSM: Issues and controversies). Symposium conducted at the meeting of the B4U-ACT, Westminster, MD. Retrieved from www. b4uact.org/wpcontent/uploads/2014/08/Kramer_slides.pptx.

Lasher, M. P., \& Stinson, J. D. (2017). Adults with pedophilic interests in the United States: Current practices and suggestions for future policy and research. Archives of Sexual Behavior, 46(3), 659-670.

Pettigrew, T. F. (1998). Intergroup contact theory. Annual Review of Psychology, 49, 65-85.

Quinn, J. F., Forsyth, C. J., \& Mullen-Quinn, C. (2004). Societal reaction to sex offenders: A review of the origins and results of the myths surrounding their crimes and treatment amenability. Deviant Behavior, 25(3), 215-232.

R Core Team (2013). R: A language and environment for statistical computing. R Foundation for statistical computing, Vienna, Austria. URL http://www.R-project.org/.

Schmidt, A. F., Mokros, A., \& Banse, R. (2013). Is pedophilic sexual preference continuous? A taxometric analysis based on direct and indirect measures. Psychological Assessment, 25, 1146-1153.
Seto, M. C. (2012). Is pedophilia a sexual orientation? Archives of Sexual Behavior, 41(1), 231-236.

Seto, M. C. (2018). Pedophilia and sexual offending against children: Theory, assessment, and intervention., 2nd ed. Washington, DC: American Psychological Association.

Stiels-Glenn, M. (2010). The availability of outpatient psychotherapy for paedophiles in Germany. Recht \& Psychiatrie, 28(2), 74-80.

Walker, A., \& Panfil, V. R. (2016). Minor attraction: A queer criminological issue. Critical Criminology, 25(1), 37-53.

WHO Regional Office for Europe. (2013). European report on preventing child maltreatment. Retrieved from http://www.euro. who.int/pubrequest

Wurtele, S. K. (2018). University students' perceptions of child sexual offenders: Impact of classroom instruction. Journal of Child Sexual Abuse, 27(3), 276-291.

Publisher's Note Springer Nature remains neutral with regard to jurisdictional claims in published maps and institutional affiliations. 